\title{
Changes in the distribution and abundance of wintering Lesser White-fronted Geese Anser erythropus in eastern China
}

\author{
XIN WANG, ANTHONY D. FOX, PEIHAO CONG, MARK BARTER \\ and LEI CAO
}

\section{Summary}

The Lesser White-fronted Goose Anser erythropus is globally threatened with an estimated world population of 25,000-28,000, of which c 20,000 winter at East Dongting Lake, China. We present here the first collation of published and unpublished data on the distribution and abundance of the species in eastern China in recent decades. Lesser White-fronted Goose numbers have declined greatly in Anhui, Jiangxi and Jiangsu Provinces between the late-1980s/early-1990s and recent years: the species' range has now mainly contracted to East Dongting Lake in Hunan. The relatively stable numbers at East Dongting Lake suggest that the population is not currently threatened, but the extreme concentration at one lake makes the species vulnerable. Lesser White-fronted Geese rely on very specific meadow vegetation exposed after water recession, so changes in water levels or recession timing, due to hydrological changes following the commissioning of the Three Gorges Dam, may affect biomass, palatability and plant species composition of the meadows. Thus, it is critically important to understand the wintering ecology and habitat needs of this threatened species at East Dongting Lake. It is also essential to conduct further synchronous Yangtze River floodplain surveys to assess the current status, distribution and habitat use of Lesser White-fronted Geese throughout the region.

\section{Introduction}

The Lesser White-fronted Goose Anser erythropus is globally threatened, designated as 'Vulnerable' (BirdLife International 2010). The world population has declined greatly since the 1940s (Lorentsen et al. 1999) to an estimated 25,000-28,000 individuals currently (BirdLife International 2010). The Russian population was thought to have decreased from 30,000-50,000 individuals to 8,000-10,000, but 22,000 were counted in autumn 2008 (www.piskulka.net/Recent $\%$ zonews.htm). The Fennoscandian population has declined from more than 10,00o birds in the early $20^{\text {th }}$ century to a few pairs (Lorentsen et al. 1999). In east Asia, the Lesser White-fronted Goose was stated to be the most numerous species in the Yangtze River floodplain over 100 years ago (Styan 1891), although other historical data indicate that the species occurred in the lower Yangtze, but was uncommon in south-eastern China (La Touche 1931-1934), and was uncommon in the middle and lower reaches of the Yangtze River (Cheng 1987); thus, there is considerable confusion about the historical status of the species in eastern China. The species was reportedly regularly sighted in Hunan, Hubei, Anhui and Jiangsu Provinces from the 1920s to 1980s (BirdLife International 2001), indicating a wide distribution in eastern China. However, at present only c.21,00o individuals occur, mostly confined to East Dongting Lake National Nature Reserve (190,00o ha) (Cao et al. 2008b, 2010), part of the second largest freshwater lake in China, smaller only than Poyang Lake. 
Despite national nature reserve status, East Dongting Lake faces many threats that could potentially affect Lesser White-fronted Geese, including massive changes in the hydrological cycle (average reduction of five weeks [20\%] in the flood pulse duration and an average c. $3 \mathrm{~m}$ lower peak height; L. Cao unpubl. data) and downstream sediment loads due to commissioning of the Three Gorges Dam (TGD) in mid-2003 (Xu et al. 2006, Yang et al. 2006, Yang et al. 2007, Zhang et al. 2011), and illegal hunting (Chen et al. 2001). Increasing pollution (Wang 2006, Yan and Zhang 2003) can also be expected to impact on wetland quality and vegetation structure, and consequently on waterbirds (Cheng et al. 2009, Fox et al. 2010, Zhang et al. 2011).

Given these serious threats to wetland habitats in the Yangtze River floodplain, the main wintering area of the Lesser White-fronted Goose in east Asia, we here present the first collation of published and unpublished data on the distribution and abundance of the species in eastern China in recent decades, and recommend further surveys and future research to improve our knowledge of the distribution and ecological needs of this threatened species.

\section{Methods}

\section{Study area}

China east of $110^{\circ} \mathrm{E}$ has traditionally been frequented by the species, especially the Yangtze River floodplain and coastal Jiangsu Province (Figure 1; Cao et al. 2008a). The Yellow River wetlands are less important, as they are invariably frozen throughout the winter (Liu 1997). Coastal areas, from the Vietnam border in the south to the Bo Sea in the north, provide extensive intertidal and subcoastal habitat suitable for geese but are less used (Cao et al. 2008b). Few waterbirds occur west of $110^{\circ} \mathrm{E}$ during the non-breeding season, as this part of China is mostly at higher elevations, particularly in the south-west, and much of it lies well to the north of the average January $0^{\circ} \mathrm{C}$ isotherm (Liu 1997).

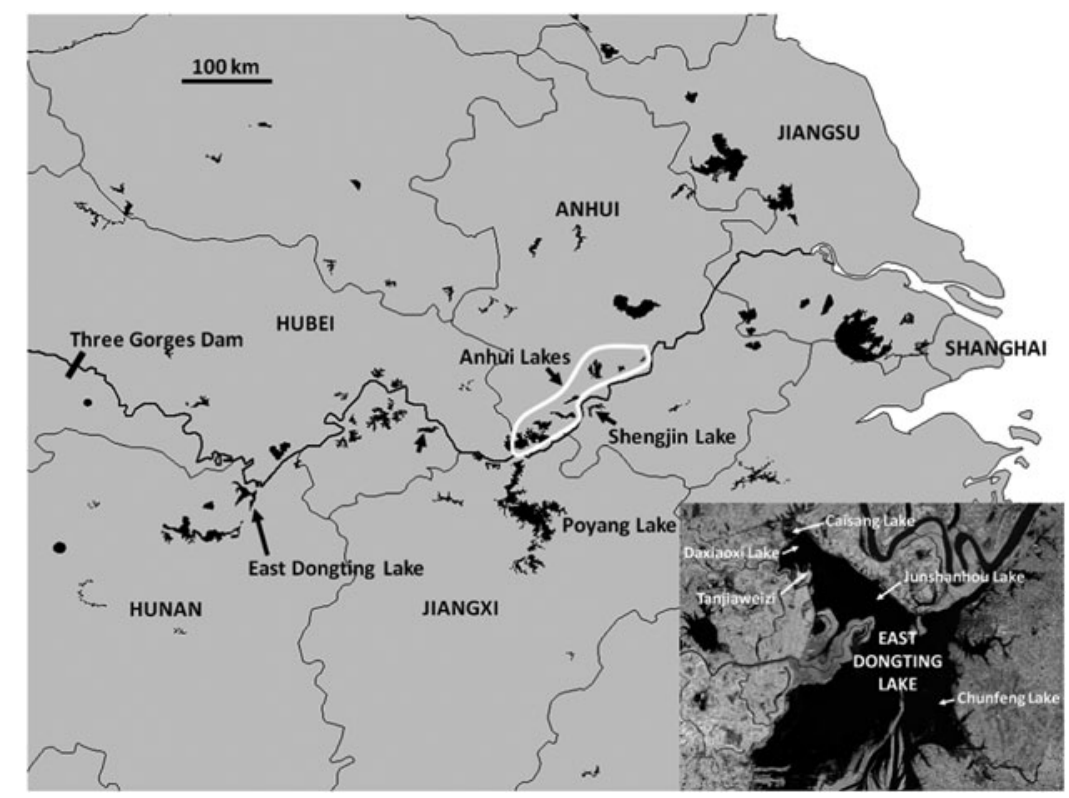

Figure 1. Location of important wetlands for Lesser White-fronted Geese within the Yangtze River floodplain: East Dongting Lake, Poyang Lake, the Anhui Lakes (Anhui Anqing Yangtze Riverine Provincial Nature Reserve) and Shengjin Lake; boundaries of the floodplain provinces and the site of the Three Gorges Dam are also shown. Lower right inset shows the most important sites within East Dongting Lake. 


\section{Data sources}

Few systematic survey data for waterbirds in East China exist before the 200os, although occasional and incomplete accounts have been published. The first synchronous surveys were conducted throughout the Yangtze River floodplain in February 2004 and 2005 covering Hunan, Hubei, Jiangxi, Anhui and Jiangsu Provinces, and Shanghai Municipality (Barter et al. 2004, 2006); the first survey also covered coastal southern Jiangsu province.

Since then, non-synchronous counts have been conducted in the following Provinces: Hunan (2005/ 06-2008/2009); Hubei (2008/2009); Jiangxi 2005/06-2009/2010); and Anhui (13-20 December 2009; 5-10 February 2010). Opportunistic counts at different periods during the wintering season complicate data interpretation but contribute to our knowledge of the consistency with which sites held important numbers of Lesser White-fronted Geese.

Because of its great importance for Lesser White-fronted Goose, key areas at East Dongting Lake (Hunan Province) were counted monthly in the 2008/2009 and 2009/2010 winters (P. Cong unpubl. data). Shengjin Lake (Anhui Province), another key waterbird wetland, has also been counted regularly during the 2008/2009 (nine times) and 2009/2010 (13 times) winters (Cheng et al. 2009, Meng 2010).

Other data sources (e.g. China Bird Report, China Birdwatch, the internet, etc.) were searched to determine the extent to which the range of the species extends outside the Yangtze River floodplain.

To assess trends in abundance and distribution, maximum annual provincial count data were divided into three periods: 1987/1988-1992/1993, 1993/1994-1998/1999 and 2004/2005-2009/2010. For each period we used the sum of the maximum counts for sites within each province.

\section{Results}

Lesser White-fronted Goose numbers have declined greatly in Anhui, Jiangxi and Jiangsu Provinces between the late-1980s/early-1990s and recent years: numbers in Hunan Province have remained relatively stable; the species' range has now mainly contracted to Hunan (Table 1 ). As we have no information on how Lesser White-fronted Geese move around during the winter, the period totals may not accurately reflect the east China wintering population size; however, it seems likely that there was a large population decline between the late-1980s/early-1990s and the mid- to late 1990s, as also occurred generally in Anatidae wintering in eastern China (Cao et al. 2008b).

Since 2002/2003, the great majority of Lesser White-fronted Geese have occurred in Hunan and Jiangxi, mostly at East Dongting Lake with occasionally large numbers present at Poyang Lake. Total numbers have been relatively stable, despite probable variations in annual breeding success, incompleteness of counts and difficulties in separating the species from Greater White-fronted Geese Anser albifrons (Table 2).

Table 1. Lesser White-fronted Goose numbers in the Yangtze River floodplain provinces from 1987/19882009/2010 (maximum counts during each period).

\begin{tabular}{lllllll}
\hline & \multicolumn{3}{l}{ Province } & & & \\
\cline { 2 - 5 } Periods & Anhui & Jiangxi & Hunan & Hubei & Jiangsu & Total \\
\hline $1987 / 1988-1992 / 1993$ & $4,850^{1}$ & $27,160^{2}$ & $20,000^{1}$ & $824^{1}$ & $11,660^{2}$ & 64,494 \\
$1993 / 1994-1998 / 1999$ & $1,150^{1}$ & $9,790^{2}$ & $13,700^{3}$ & $430^{4}$ & $650^{2}$ & 25,720 \\
$2004 / 2005-2009 / 2010$ & $564^{5,6}$ & $6,343^{7}$ & $15,234^{8}$ & $0^{9}$ & $0^{9}$ & 22,141 \\
\hline
\end{tabular}

1: Waterbird Specialist Group of Chinese Ornithological Association (1994); 2: David Lee (pers. comm.); 3: Lei and Yang (1999); 4: Ge et al. (2005). 5, 6: Cao unpubl. data; 7: unpubl. data from Poyang Lake Nature Reserve; 8: Count data from four key sites at East Dongting Lake (L. Cao unpubl. data), which held over $90 \%$ of Lesser White-fronted Geese at Dongting Lake in the 2004 and 2005 winters; 9: WWF survey (Barter et al. 2004, 2006). 
Table 2. Lesser White-fronted Goose numbers in the Yangtze River floodplain provinces from 2002/2003 to 2009/10.

\begin{tabular}{lccllllr}
\hline Winter & Anhui & Jiangxi & Hunan & Hubei & Jiangsu & Shanghai & Total \\
\hline $2002 / 2003$ & - & $856^{5}$ & $16,551(1)^{11}$ & $1^{19}$ & - & - & 17,408 \\
$2003 / 2004$ & 0 & 9 & $16,928(5)^{12}$ & 0 & 0 & 0 & 16,937 \\
$2004 / 2005$ & 0 & 0 & $8,636(0)^{13}$ & 0 & 0 & 0 & 8,636 \\
$2005 / 2006$ & - & $1345^{6}$ & $14,400^{14}$ & - & - & - & 15,745 \\
$2006 / 2007$ & - & $6343^{7}$ & $11,620^{15}$ & - & - & - & 17,963 \\
$2007 / 2008$ & $401^{1}$ & $3365^{8}$ & $15,234^{16}$ & - & - & - & 19,000 \\
$2008 / 2009$ & $12^{2}$ & $1197^{9}$ & $11,432^{17}$ & - & - & - & 12,629 \\
$2009 / 2010$ & $564^{3,4}$ & $263^{10}$ & $12,257^{18}$ & - & - & - & 13,084 \\
\hline
\end{tabular}

Notes: 2003/2004 and 2004/2005 counts conducted in early February (Barter et al. 2004, 2006); italics identify incomplete counts which did not cover the complete province, but probably few birds occurred outside counted areas; '-' indicates no data available. 1 and 4: 25-26 February 2008; 2: 5 February 2009; 3: 6 February 2010; 4:10 February 2010; all L Cao unpubl. data; 5-10: unpubl. data from Poyang Lake National Nature Reserve, 5 and 8 are January counts, 6 and 7 are December counts, 9 and 1o are February counts; 11: January count (Barter and Lei 2003); 11-13:1, 5 and o birds, respectively, outside East Dongting Lake; 14, 15 and 17: unpubl. data from East Dongting Lake (February counts); 16 and 18 : data from four key sites at East Dongting Lake (L. Cao unpubl. data), which held over 90\% of Lesser White-fronted Geese in Dongting Lake in 2004 and 2005 winter; 19: January count (Barter and Lei 2003).

Lesser White-fronted Geese concentrate at three sites (all February counts) within East Dongting Lake: Chunfeng, Daxiaoxi and Caisang Lakes (Figure 1 inset), with numbers declining at Daxiaoxi Lake in recent years and a smaller increase at Caisang Lake (Table 3).

\section{Discussion}

Little quantitative information is available on wintering numbers before the early 200os, with the only reasonably comprehensive surveys being conducted in the 1988-1992 period, although there may be some doubt about the accuracy of these counts given the difficulty of separating Lesser from Greater White-fronted Geese and the lack of good optical equipment in China at that time. However, historical data indicate that there has been a large decline in abundance and range within eastern China for many Anatidae species (BirdLife International 2001), including Lesser White-fronted Geese (Sowerby et al. 1943, Cao et al. 2008a). Syroechkovskiy (2006) provides further evidence for the decline in abundance suggesting that the Eastern Russia-China breeding population has decreased from 220,000 in the mid- 1980 os to c.40,000 in 2002/2003, although he believes that it is possible that some of these birds are wintering west of China - a suggestion which explains why only c.50\% of the estimated 2002/2003 population winter in East Asia

Table 3. Numbers of Lesser White-fronted Goose at the key sites in East Dongting Lake during simultaneous February counts in 2002/2003-2009/2010 winters.

\begin{tabular}{|c|c|c|c|c|c|c|}
\hline Winter & Caisang Lake & Daxiaoxi Lake & Chunfeng Lake & Tanjiaweizi & Junshanhou Lake & Total \\
\hline $2002 / 2003$ & o & 10,550 & 6,000 & - & - & 16,550 \\
\hline $2003 / 2004$ & 240 & 11,490 & 3,969 & 320 & 749 & 16,174 \\
\hline $2004 / 2005$ & 30 & 8,546 & 44 & $\mathrm{O}$ & o & 8,620 \\
\hline $2007 / 2008$ & 1,573 & 9,565 & 4,065 & - & - & 15,203 \\
\hline $2008 / 2009$ & 1,477 & 6,940 & - & 1,600 & - & 10,017 \\
\hline $2009 / 2010$ & 1,420 & 4,757 & 6,080 & - & - & 12,257 \\
\hline
\end{tabular}

Notes: Counts conducted in 2002/2003 from Barter and Lei (2003); counts in 2003/2004 and 2004/2005 from Barter et al. (2004, 2006); remaining counts all L. Cao (unpubl. data); '-' indicates no data available. 
(Cao et al. 2008b). In summary, despite patchy and possibly inaccurate historical data it seems that there has been a large decline in Lesser White-fronted Goose numbers in recent decades.

Lesser White-fronted Geese were probably more widespread in the 1980s and 1990s than is currently the case, with greater numbers in Anhui, Jiangxi and Jiangsu Provinces than in recent years. Although formerly more widespread in the Yangtze River floodplain and coastal Jiangsu, the Lesser White-fronted Goose is now mainly confined to East Dongting Lake. Numbers seem to be stable since 2002/2003, at around 20,000 individuals in mid-winter. Further analysis and discussion of possible causes of changes in status is limited by lack of knowledge on the wintering ecology of the species, e.g. arrival and departure dates, movements within eastern China, age ratios and food preferences.

Reasons for the possible range contraction and reduction in numbers during the 1990s are likely a combination of factors including habitat loss and degradation in the Yangtze River floodplain (Lu 1996, NWCAPC 2000, He and Zhang 2001), hunting (Lu 1993), and the specialised feeding ecology of the species. At East Dongting Lake, the species aggregates in dense monocultures of short graminoid plants, exposed by falling water levels that are not exploited by other geese (P. H. Cong unpubl. data). Hence the species, as elsewhere in its range, may be adapted to exploiting highly specific winter habitats that make it more susceptible to habitat change than other goose species. However we have little information concerning the habitat preferences elsewhere within the historical wintering range and, hence, whether a decline in short graminoids may have led to range contraction.

East Dongting Lake is relatively well protected and the current timing and pattern of water level recession has enabled Lesser White-fronted Geese (as well as Bean Geese Anser fabalis and Greater White-fronted Geese) to utilise the new growth of various graminoid species in succession (P. H. Cong unpubl. data, L. Cao unpubl. data). However, the Three Gorges Dam could affect water level drawdown patterns, especially by exposing Carex sedge beds at East Dongting Lake earlier, affecting the height and hence attractiveness of the sward.

Poyang Lake and East Dongting Lake National Nature Reserves support most of the wintering Lesser White-fronted Goose population; Shengjin Lake National Nature Reserve supports the majority of the small remaining numbers found in the floodplain. Human disturbance is much reduced in nature reserves, especially national nature reserves, because there is less agriculture, fishing, poaching and reclamation than in unprotected wetlands. The relatively stable numbers at East Dongting Lake suggest that the population is not currently threatened, but the extreme concentration at one lake makes the species vulnerable, especially to external factors such as hydrological change. Lesser White-fronted Geese rely on very specific meadow vegetation exposed after water recession, so changes in water levels or recession timing may affect biomass, palatability and plant species composition of the meadows. Within East Dongting Lake, Lesser White-fronted Geese are highly concentrated at just three relatively restricted sites, with the distribution between these changing in recent years.

It is critically important to understand the wintering ecology and habitat needs of this threatened species throughout the current wintering range, and to determine the best means of providing and protecting its grazing habitat, potentially by regulating water levels in a scientifically defensible way. This is particularly important at East Dongting Lake which supports the great majority of Lesser White-fronted Geese wintering in the eastern China. It is also essential to conduct further synchronous surveys in the Yangtze River floodplain to assess the current status, distribution and habitat use of Lesser White-fronted Geese throughout the region.

\section{Acknowledgements}

The study was supported by Chinese Academy of Sciences Innovation Project (Grant No. KZCX2YW-QN503), the National Natural Science Foundation of China (Grant No.31071941) and the University of Science and Technology of China Graduate School Educational Innovation Base. We wish to thank two anonymous reviewers for their helpful comments which helped greatly in improving the paper. 


\section{References}

Barter, M. and Lei, G. (2003) Survey for Dunlin Calidris alpina in the Lower Chang Jiang (Yangtze River) Basin, China, during January 2003. Unpublished Report to US Fish and Wildlife Service and US Geological Survey, Anchorage, Alaska, USA.

Barter, M., Chen, L., Cao, L. and Lei, G. (2004) Waterbird survey of the middle and lower Yangtze River floodplain in late January and early February 2004. Beijing, China: China Forestry Publishing House.

Barter, M., Lei, G. and Cao, L. (2006) Waterbird survey of the middle and lower Yangtze River floodplain (February 2005). Beijing, China: China Forestry Publishing House.

BirdLife International (2001) Threatened birds of Asia: International Red Data Book. Cambridge, UK: BirdLife International.

BirdLife International (2010) Anser erythropus. In: IUCN 2010. IUCN Red List of Threatened Species. Version 2010.4. $<$ www.iucnredlist.org $>$. Downloaded on o7 April 2011.

Cao, L., Wang, X., Wang, Q. S. and Barter, M. A. (2008a) Wintering anatidae in China: a preliminary analysis. Casarca 11: 161-180.

Cao, L., Barter, M. and Lei, G. (2008b) New Anatidae population estimates for eastern China: implications for current flyway estimates. Biol. Conserv. 141: 2301-2309.

Cao, L. Zhang, J., Barter, M. and Lei, G. (2010) Anatidae in eastern China during the non-breeding season: geographical distributions and protection status. Biol. Conserv. 143: 650-659.

Chen, K. L., Li, Z. W., Jiang, Y. and Liu, X. Z. (2001) Report on wintering waterbird hunting status at Poyang and East Dongting Lake. Beijing, China: Wetlands International - China Programme. (In Chinese and English).

Cheng, T. H. (1987) A synopsis of the avifauna of China. Beijing, China: Science Press.

Cheng, Y. Q., Cao, L., Barter, M., Xu, W. B., Zhang, Y. and Zhao, M. J. (2009) Wintering waterbird survey at the Anhui Shengjin Lake National Nature Reserve, China 2008/9. Hefei, China: University of Science and Technology of China Press.
Fox, A. D., Cao, L., Zhang, Y., Barter, M., Zhao, M. J., Meng, F. J. and Wang, S. L. (2010) Declines in the tuber-feeding waterbird guild at Shengjin Lake National Nature Reserve, China - a barometer of submerged macrophyte collapse. Aquat. Conserv. DOI. 10.1002/aqc.1154.

Ge, J. W., Cai, Q. H., Hu, H. X., Liu, J. K., Cao, G. B. and Liu, S. X. (2005) On species diversity and population size of rare, endangered and national key protected waterfowls in Hubei Province, China. Resources and Environment in the Yangtze Basin 14: 50-54. (In Chinese).

He, Y. and Zhang, M. X. (2001) Study on wetland loss and its reason in China. Chi. Geogr. Sci. 11: 241-245.

La Touche, J. D. D. (1931-1934) A handbook of the birds of Eastern China. London, UK: Taylor and Francis.

Lei, G. and Yang, Y. Q. (1999) Summary report on wintering migrants in East Dongting Lake, 1998. Newsletter for Wetlands 2: 18. (Beijing, China: Wetlands International - China Programme).

Lorentsen, S.-H., Øien, I. J., Aarvak, T., Markkola, J., von Essen, L., Faragó, S., Morozov, V., Syroechkovsky, E., Jr and Tolvanen, P. (1999) Lesser White-fronted Goose Anser erythropus. Pp. 144-161 in J. Madsen, G. Cracknell and T. Fox, eds. Goose populations of the Western Palearctic. A review of status and distribution. Wageningen, The Netherlands: Wetlands International. (Wetlands International Publication No. 48).

Liu, M. G., ed. (1997) China geography illustrated. Beijing, China: China Map Publishing Company.

Lu, J. J. (1993) The utilisation of migratory waterfowl in China. Pp. 90-92 in M. Moser and C. Prentice, eds. Waterfowl and wetlands conservation in the 1990s: a global perspective. Slimbridge, UK: IWRB. (IWRB Special Publication No. 26).

Lu, J. J. (1996) The status and conservation needs of Anatidae and their habitat in China. Pp. 129-142 in China ornithological research. Beijing, China: China Forestry Publishing House. 
Meng, H. X. (2010) Wintering waterbird survey at the Anhui Shengiin Lake National Nature Reserve, China 2009/2010. Degree Thesis. Hefei: University of Science and Technology of China. (In Chinese, with English abstract).

NWCAPC (2000) National wetland conservation action plan for China. Beijing, China: State Forestry Administration.

Sowerby, A de C. (1943) Birds recorded from or known to occur in the Shanghai area. Notes d'Ornithologie Musee Heude 1: 1207.

Styan, F. W. (1891) On the birds of the Lower Yangtze Basin - Part II. Ibis 12: 481-510.

Syroechkovskiy, J. E. E. (2006) Long-term declines in Arctic goose populations in eastern Asia. Pp. 649-662 in G. C. Boere, C. A. Galbraith and D. A. Stroud, eds. Waterbirds around the world. Edinburgh, UK: The Stationery Office.

Wang, B. (2006) Cultural eutrophication in the Changjiang (Yangtze River) plume: History and perspective. Estuarine Coast and Shelf Science 69: 471-477.

Waterbird Specialist Group of Chinese Ornithological Association (1994) Waterbird research in China. Shanghai, China: East China Normal University Press.
Xu, K., Milliman, J. D., Yang, Z. and Wang, H. (2006) Yangtze sediment decline partly from Three Gorges Dam. EOS, Trans. Am. Geophys. Union 87: 185-196.

Yan, W. and Zhang, S. (2003) How do nitrogen inputs to the Changjiang basin impact the Changjiang River nitrate: A temporal analysis for 1968-1997. Global Biogeochem. Cycles 17: 1091.

Yang, S. L., Zhang, J. and Xu, X. J. (2007) Influence of the Three Gorges Dam on downstream delivery of sediment and its environmental implications, Yangtze River. Geophys. Res. Lett. 34: L10401, doi:10.1029/2007GLo29472.

Yang, Z., Wang, H., Saito, Y., Milliman, J. D., Xu, K., Qiao, S. and Shi, G. (2006) Dam impacts on the Changjiang (Yangtze) River sediment discharge to the sea: The past 55 years and after the Three Gorges Dam. Water Resour. Res. 42: Wo4407, doi:10.1029/2005WRo03970.

Zhang, Y., Cao, L., Barter, M., Fox, A. D., Zhao, M. J., Meng, F. J., Jiang, Y. and Zhu, W. Z. (2010) Changing distribution and abundance of swan geese in the Yangtze River floodplain: the likely loss of a very important site. Bird Conserv. Int. $21: 36-48$.

XIN WANG, PEIHAO CONG, MARK BARTER, LEI CAO*

University of Science and Technology of China, 96 Jinzhai Road, Hefei, Anhui 230026, China.

\section{ANTHONY D. FOX}

Department of Wildlife Ecology and Biodiversity, National Environmental Research Institute, Aarhus University, Kalø, Grenåvej 14, DK-8410 Rønde, Denmark.

*Author for correspondence; e-mail: caolei@ustc.edu.cn

Received 10 January 2011; revision accepted 7 May 2011;

Published online 11 April 2012 